\title{
Desenvolvimento profissional de professores: prática evolucionária, reforma curricular e mudança cultural
}

\author{
Joan Solomon*
}

\section{Status profissional}

Os professores constituem o patrimônio cultural mais importante na educação de um país, e o principal patrimônio destes professores não é o domínio de conteúdos específicos ou pedagógicos per se, embora isto seja fundamental. Estou convencida de que esta entidade oculta é o status dos professores, tanto aos olhos da comunidade como aos seus próprios olhos. Se o panorama educacional de um país chega a um ponto no qual os professores são considerados como pessoas que não conseguiram tornar-se intelectuais universitários, ou, pior ainda, que os professores consideram suas próprias carreiras como tal, então a educação nesse país enfrenta graves problemas! Os professores são profissionais na antiga arte de ensinar. Em algumas culturas, como a das comunidades budistas e judaicas tradicionais, ser professor era ser considerado um membro respeitado da sociedade. É por este motivo que emprego a expressão utilizada na Open University, Educação Profissional Continuada (Continued Professional Education - CPD) para designar aquilo que é freqüentemente denominado de Educação de Professores em Serviço (in-service education of teachers INSET). É claro que nós todos precisamos de educação; de fato, necessita-

* Ph.D., Center for Science Education, Open University, Reino Unido. Trad.: Ms. Vivian Leyser da Rosa, Universidade Federal de Santa Catarina, Brasil. 
mos de educação ao longo de toda a vida, e, neste aspecto, os professores não se diferenciam. Porém, não devemos utilizar a Educação de Professores em Serviço para lhes fornecer habilidades profissionais para ensinar, tampouco inovações para a sala de aula, ou reformas curriculares. No presente artigo argumentarei que todos estes três aspectos pertencem, de forma mais apropriada, à Educação Profissional Continuada.

Antigamente acreditava-se que o status profissional era conferido por duas qualidades:

(a) o domínio de um conjunto de conhecimentos específicos, e (b) idealismo.

Atualmente, em plena era da informação, não há mais segurança sobre a primeira destas qualidades. Nenhum tipo de conhecimento comunicável permanece exclusivo e especial no cotidiano da Internet. A segunda qualidade, a de um serviço prestado aos outros, que outrora constituía o símbolo dos profissionais, hoje é mais um direito público do que uma dádiva. A qualidade profissional está sujeita a constante monitoramento no sentido de assegurar os interesses dos beneficiados pelos serviços. Na profissão médica, este direcionamento pode ser claramente detectado no crescente apelo público a expedientes legais ao invés da confiança na relação médico/paciente. Os médicos lutam não apenas no sentido de manter sua liberdade profissional para prescrever e tratar seus clientes da forma que julgam mais adequada, como também para manter e regulamentar seus próprios padrões de qualidade na realização de cirurgias e na recuperação de pacientes. Porém, no que diz respeito à educação, ambas as batalhas parecem ter sido perdidas. Na Inglaterra, atualmente, os professores são rigidamente 'administrados' por comissões de educadores mais experientes e através de rigorosas inspeções do governo. Mesmo assim, esses professores não perderam totalmente seu poder de inovação, nem sua maneira de avaliar o ensino de ciências que praticam.

Donald Schon (1983) escreveu muito bem sobre a reflexão-na-ação. Diz este autor:

À medida que tentamos entender a natureza da reflexão-na-ação, bem como as condições que a encorajam ou a inibem, estudamos um processo cognitivo que é amplamente influenciado por 'emoções cognitivas' e pelo contexto social... (p. 322)

A primeira dessas influências mencionadas por Schon coloca juntos dois termos quase que opostos. O que significaria praticar uma emoção cognitiva? Schon explica que utiliza este termo para descrever os senti- 
mentos do praticante sobre seu próprio desempenho. Podemos nos referir a isto, de forma mais geral, como uma reflexão sobre os valores nos quais está baseada a ação profissional.

Há uma relação muito estreita entre ações e valores. Diferentes filósofos, como Dennet (1981), Ziman (1978) e Popper (1965), concordam que os valores baseados nas crenças estão na natureza mesma das ações que eles desencadeiam, e não simplesmente no conhecimento. Mesmo Karl Popper (1972), filósofo positivista da ciência preocupado com a natureza do conhecimento, escreveu enfaticamente: Agimos a partir das nossas crenças e não, como ele deixa implícito, a partir do nosso conhecimento. Há também uma ligação no sentido oposto. A ação e a reflexão sobre esta constróem um sentido de valor. As distinções entre os valores, conhecimento, crença e ação dos professores nos mostram como estes reagem a novos desafios. Handal e Lauvas (1987) escreveram, de forma significativa, sobre o que chamam de teoria prática dos professores, que é dinâmica, constituindo uma base para a ação, e ainda assim sujeita a mudanças à medida que o educador vivencia novas experiências e forma novos valores.

\footnotetext{
A teoria prática (dos professores) se refere a um sistema pessoal de conhecimento, experiência e valores, que é relevante para a prática educacional num dado momento, sistema este que é individual e integrado, embora em permanente estado de mudança. (p. 79)
}

O segundo fator mencionado por Schon é externo. Ele o denomina contexto social, o qual pode, a qualquer momento, incluir o comportamento do aluno, o tamanho da turma, os recursos disponíveis, e até mesmo as condições do tempo (a maioria dos professores britânicos concorda que ventos fortes provocam agitação e indisciplina na sala de aula!). Este aspecto também foi apontado por Deanne Kuhn (1986) em um estudo sobre a contribuição da psicologia para os objetivos da Educação para a Reflexão. Esta autora escreveu que era necessário considerar todas 'as habilidades para pensar, no contexto dos domínios de conteúdos específicos'. Isto pode ser transferido facilmente para o contexto dos professores refletindo em plena sala de aula durante o intenso processo de aprendizado. John Elliot (1991) coloca uma questão similar, ao se referir à

compreensão holística das situações, como base para a prática profissional, ao invés de entendê-las exclusivamente em termos de um grupo particular de categorias determinadas por especialistas. (p. 311) 
Isto nos fornece algumas idéias básicas para planejar cursos que promovam a CPD. Em primeiro lugar, observamos que a ação profissional está baseada em valores, e, segundo, que estes valores não se referem apenas a algum campo abstrato do conhecimento, mas sim ao difuso domínio das salas de aula, onde os alunos aprendem e os professores ensinam.

\section{A teoria em ação: os professores implementando um novo currículo}

Precisamos agora expandir a ampla idéia de prática e valores com a finalidade de incluir as decisões sobre as mudanças curriculares, que hoje constituem uma das tarefas mais fundamentais do profissional professor. A expressão 'teoria em ação', utilizada para descrever o problema central da educação, quando esta é vista de forma direcionada, do governo e da universidade para a sala de aula, é mais freqüentemente utilizada nos EUA do que na Inglaterra. Se os pesquisadores em educação já não tiverem vivenciado o papel de um profissional professor, eles terão a tendência de encarar a implementação de práticas novas e melhores, por eles propostas, como sendo obliteradas pelo professor (p. ex., Roberts, 1980; Radford, 1998). Este é um enfoque muito simplista. Os currículos norte-americanos de Ciências, nas décadas de 1960 e 1970, foram elaborados por cientistas universitários como uma reação ao lançamento da Sputnik, e diz-se que eram 'à prova de professores' (uma expressão bastante injusta para com aqueles que tinham uma dedicação vitalícia à prática de ensinar e aprender). Demonstrou-se que essa reforma não funcionou (Kyle, 1984; Duschl, 1990). Os novos esquemas nunca foram colocados em prática na sala de aula, e não poderiam mesmo, por sua própria natureza. Como poderia um professor implementar ativamente um programa que teoricamente o excluía?

$\mathrm{Na}$ Inglaterra, sempre tentamos incluir os professores tanto no planejamento como na implementação das inovações curriculares, dentro das limitações de tempo permitidas pelo governo. Esta atitude não só é valorizada pelos professores como também é uma condição necessária (embora não suficiente) para o sucesso de qualquer inovação. Num estudo sobre a postura e o comportamento de professores em relação à implementação de mudanças, Waugh e Godfrey (1993) mostraram que as variáveis funda- 
mentais foram as atitudes destes em relação ao sistema anterior, sua participação no processo de mudança e o apoio percebido da parte de outros professores. Este tipo de enfoque fornece uma definição mais moderna do profissionalismo dos professores, e deve se refletir na sua CPD.

A INSET para o ensino fundamental de Ciências, que foi fornecida às pressas para implementar o primeiro e único Currículo Nacional para a Inglaterra e o País de Gales, em 1989, quando poucos professores estavam prontos para ensinar tanto os conteúdos como os processos, também apóia esse enfoque. Este tipo barato de treinamento, que o governo denominou de "modelo em cascata", não funcionou (Harland e Kinder, 1997). Os motivos desta falha são interessantes. Não foram tanto os conteúdos, nem mesmo os processos, que foram passados adiante de forma ineficiente a partir da fase inicial do treinamento para as seguintes. Faltaram os valores implícitos, sobre o que e porque ensinar, de importância tão vital como parte da reflexão profissional em ação. Isto significa que não foi transmitida, de um nível de professores ao seguinte, nenhuma compreensão holística do valor e do propósito da educação em Ciências, e não houve nenhum acesso às crenças construídas pelos valores dos próprios professores, os quais poderiam ser honestamente inseridos na ação profissional.

Há outra evidência confirmadora que pode ser adicionada a este panorama. Appleton (1995) relata de que forma um curso pré-serviço, sobre o tópico "energia", conseguiu afetar a confiança de professores de Ciências do ensino fundamental, no sentido da sua habilidade para ensinar Ciências como um todo. Não foi tanto o conteúdo específico, bastante reduzido, que modificou a auto-percepção destes professores em relação ao seu potencial, mas sim as atitudes destes em relação à Ciência como um todo. Isto foi facilitado de duas maneiras: primeiro, mostrando de que forma os alunos se beneficiam quando realizam suas próprias investigações, aprendendo conhecimentos científicos valiosos durante o processo; e, segundo, enfatizando que a Ciência, incluindo a física, era acessível tanto para as mulheres como para os homens. Ambos os fatores deram apoio à identidade profissional da maioria feminina dos alunos do curso. Isto permitiu que os mesmos imaginassem de que forma seus futuros alunos de fato aprenderiam ciências com eles, apesar de sua própria falta de conhecimento dos conteúdos. 


\section{A ação para mudança vista como evolução}

Até aqui, o argumento não foi além do enfoque útil empregado por Schon, em relação à reflexão-em-ação dos professores. Precisamos agora de um enfoque que nos permita avançar da escala reduzida da sala de aula para uma escala maior de reforma. O que proponho aqui é o uso do modelo darwiniano de evolução, aplicado como uma analogia à mudança educacional.

Se olharmos para um sistema qualquer, capaz de produzir uma gama de variações, então a primeira das condições para as mudanças evolutivas já está colocada. A única outra condição necessária é um processo de avaliação bastante draconiano, ativo no 'habitat', que eliminará variações 'ruins'. Daí podemos então deduzir que algo como uma seleção natural está ocorrendo. Isto poderia se aplicar, igualmente, à comercialização de novos produtos, ou à capina de um canteiro de flores. Donald Campbell (1960) denominou este processo de "Variação Cega e Retenção Seletiva" (Blind Variation and Selective Retention - BVSR) e o defende como um processo geral de aprendizado.

No contexto da pesquisa-ação sobre professores, esse modelo explora a reflexão-em-ação dos mesmos, a qual, como um processo de geração de variações, sugere diferentes maneiras de ensinar algum tópico familiar. O segundo processo inicia com as reações dos aprendizes em potencial no "domínio-rico-em-conteúdos" da sala de aula, no qual o habitat selecionará as estratégias de ensino que funcionarão e aquelas que não surtirão efeitos. Não é difícil reconhecer o processo evolutivo BVRS no que se segue:

1. As variações podem depender de experiência prévia, mas iniciam um processo criativo.

2. A seleção é uma reação quase instintiva às primeiras tentativas, e pode conduzir ao abandono do projeto como um todo (reflexão-em-ação).

3. Inicia-se um segundo nível de seleção, quando as aulas subseqüentes indicam se o aprendizado é durável e correto, ou não. Podem também surgir idéias melhores num segundo momento da inovação.

Portanto, a mudança educacional evolui através da retenção seletiva de características desejáveis em pelo menos dois habitats bem diferenciados: um é a sala de aula, no momento da introdução do assunto, e o outro (se tudo correr bem) opera posteriormente na mente do professor observador e reflexivo. A CPD almeja expandir este segundo processo. Se 
interferirmos precocemente no primeiro estágio, quando as variações ainda estão brotando na mente do professor, poderá haver eliminação prematura de todas as novas idéias. Precisamos enfocar questões como: Por que a inovação funcionou? Em que sentido esta inovação melhorou o aprendizado? Esta inovação pode ser aperfeiçoada?

\section{As reformas impostas pelo governo}

Em relação às maiores levas de reforma educacional dos últimos cinqüenta anos, devemos levar em conta algumas das últimas manifestações de Donald Campbell (1960), sobre como a BVSR poderia ser aplicada às condições sociais. A educação é, de forma tão clara, uma expressão sóciocultural, e esperamos aprender sobre como a boa educação poderia ser selecionada da má educação. Entretanto, Campbell advertiu contra esta comparação.

O Darwinismo social vinculado aos nomes de Herbert Spencer e de Adolf Hitler tem sido rejeitado universalmente por ser intoleravelmente elitista e racista. Foi utilizado para defender ações que a sociedade deveria seguir para reforçar os processos seletivos, tidos como não suficientemente operantes para assegurar a 'sobrevivência dos mais aptos', rejeitada pela maioria das pessoas civilizadas. Esta forma brutal de pensamento defendia que os fracassados e desempregados não deveriam contar com a ajuda do Estado, que os alunos lentos deveriam ser excluídos dos sistemas escolares, e que os doentes crônicos deveriam ser esterilizados. Não havia absolutamente nenhum respeito pela variação e pelas novas idéias, facetas tão importantes na BVSR. A crueldade era utilizada para reforçar a seleção que deveria ocorrer naturalmente em momentos mais instáveis da existência humana.

A dificuldade nas reformas educacionais de larga escala é identificar quais entidades educacionais estão lutando e se modificando no sentido da sobrevivência, em condições políticas novas e possivelmente adversas. Será que os professores constituem entidades que estão lutando para existir ? Ou será que o são os alunos? Nenhum governo dirigiria as reformas diretamente para remover qualquer uma destas entidades, no caso 'delas' fracassarem, uma vez que, preliminarmente, todos os professores se opõem às mudanças, e todas as crianças têm pais que são eleitores! 
O poder para as reformas educacionais em larga escala reside numa variedade de grupos (administradores, políticos, professores) e quase a totalidade do público que, geralmente, também são pais ou avós de crianças em idade escolar. Esta diversidade constitui um habitat muito complexo e perigoso para a evolução de novos métodos educacionais, uma vez que é quase impossível agradar a todos.

As escolas e seus dirigentes tentam sobreviver neste meio; suas necessidades, como as de qualquer organismo vivo num habitat não bem definido, são a de encontrar um nicho seguro para sua existência, e de estar permanentemente em alerta em relação ao perigo. A maioria dos países permite alguma variação em suas escolas, mas apenas dentro do meio cultural que lhes é peculiar. Este fator, isoladamente, faz com que as grandes comparações internacionais sobre o ensino de ciências não tenham sentido, como a iniciativa TIMSS, que procura equacionar respostas a questões factuais com o desempenho onde não há cultura comum para atribuir significado ao termo 'desempenho educacional'. Não é possível comparar países tão diferentes como, por um lado, Japão e Singapura, onde a cultura determina a total submissão do aluno à preparação para obter boas notas nos exames e, por outro, a Dinamarca, onde as escolas são legalmente proibidas de separar os alunos por suas habilidades, e onde se gasta, por aluno, mais do que em qualquer outro país europeu.

A escola é uma forma especial de instituição social. O diretor de escola britânico, que ainda faz preleções diárias sobre o ethos da escola para alunos e professores, é mais do que uma simples caricatura. Ele defende uma instituição que afirma ser capaz de pensar e planejar por si mesma. Ludwik Fleck (1935) foi o primeiro a reconhecer que todas as instituições sociais são coletivos de pensamento, uma idéia posteriormente adotada e reconhecida por Thomas Kuhn na sua emergente filosofia do paradigma de grupo na ciência. A escola também é um coletivo de pensamento, uma entidade reconhecível na paisagem educacional. Mary Douglas, explorando o tema das instituições sociais em 1987, adverte que não é qualquer lotação de ônibus que forma uma instituição; os indivíduos precisam ter mentes em comum. Esta é exatamente a saudação matinal do diretor de escola aos colegas e alunos: não é tanto uma memória do lugar da escola no passado, ou sobre o seu lugar na atualidade, mas sim uma tentativa de formar uma mente institucional em comum.

É possível fornecer um exemplo de pesquisa sobre o poder institucional das escolas. Foi feito um pequeno estudo exploratório sobre os fatores que facilitam as mudanças dos estilos de ensinar ciências, 
encomendado e publicado pela revista New Scientist (Solomon, 1987). Embora houvesse consenso sobre a auto-motivação do professor inglês de ciências dos anos 80, esse estudo sugeriu que o Departamento de Ciências, que constitui a própria voz da escola no que diz respeito aos méritos de toda e qualquer inovação no ensino da área, já estava forçando os professores a se encaixar num molde institucional. No grupo de professores entrevistados para essa pesquisa, nenhum que tivesse se oposto a uma norma ou prática apoiada pelo responsável pela área de ciências ou pelo seu grupo de técnicos conseguiu efetuar qualquer tipo de mudança de caráter durável (ver também Vesilind e Jones, 1998).

Isso é concomitante a uma forma de pensar institucionalizada e explica a impotência dos professores como indivíduos. Mary Douglas referese a Michel Foucalt, que criticou duramente todas as instituições sociais pela forma pela qual estas constrangem mentes e corpos. A autora acrescentou que as instituições freqüentemente fixam processos que devem ser essencialmente dinâmicos, e ocultam suas influências. É a imposição desse constrangimento que se opõe às fluidas inovações do profissional professor. As reformas em larga escala, impostas pelo governo, podem ser adaptadas pelo professor para se ajustarem às capacidades de aprendizado das crianças apenas quando o controle institucional se afrouxa.

As reformas governamentais de 1988 impuseram sanções contra quaisquer escolas que não conseguissem incluir seus alunos nos padrões determinados pelas autoridades educacionais, e determinaram a publicação dos resultados de exames escolares em tabelas nacionais. Ao financiar as escolas de acordo com o número de alunos que conseguissem atrair, o governo esperava que a competição entre as escolas e as escolhas dos pais forçassem estas escolas a atuar da melhor forma possível, com a finalidade de fazer seus alunos passarem pelos testes e exames. Ao efetuar cortes drásticos nos fundos disponíveis para os sistemas educacionais locais, o governo também eliminou os financiamentos adicionais para as escolas de comunidades carentes. Assim, vemos tanto as 'forças de mercado' como alguns aspectos do Darwinismo social convergindo sobre as escolas do país, num esforço para impor as reformas. Pesquisas estatísticas recentes (Levacic, 1998) mostraram que não foi a competição entre as escolas, onde esta ocorreu, nem as forças de mercado associadas que elevaram os padrões escolares. Foi a retirada da ajuda financeira para escolas de áreas menos favorecidas, responsáveis pela diminuição dos padrões. Estas escolas foram identificadas de forma pejorativa, colocadas sob "condições especiais" e até mesmo fechadas. 


\title{
Deslocamento cultural
}

Existe um terceiro tipo de reforma educacional que não está nem confinada à pequena escala de sala de aula da pesquisa-ação dos professores, nem direcionada por decretos governamentais. Tomarei como exemplo disto o movimento educacional Ciência, Tecnologia e Sociedade ${ }^{1}$ (Science, Technology and Education - STS) que floresceu principalmente entre a metade da década de 70 e a metade dos anos 80. Em 1980 John Ziman escreveu com entusiasmo sobre STS, demonstrando um reconhecimento de que, assim como outras iniciativas educacionais, este movimento se enquadra na cultura contemporânea.

\begin{abstract}
'O movimento STS pertence ao nosso próprio tempo e à nossa forma de civilização. Ele afeta diretamente instituições educacionais, educadores e professores. Escrevo em virtude da minha experiência pessoal com tal tipo de ensino, de um comprometimento pessoal com esta questão e devido à amizade de outras pessoas que perceberam o mesmo impacto.' (Ziman, 1989, p.4, minha ênfase)
\end{abstract}

Os fatores que causaram a promoção do movimento STS não foram aqueles de seleção darwiniana entre uma grande variedade de idéias. O movimento surgiu a partir de um notável direcionamento em comum, em vários países. $\mathrm{O}$ evento que o desencadeou foi provavelmente a reação às bombas atômicas, cujas detonações finalizaram a Segunda Guerra Mundial. Durante os anos 50 e 60, em vários países e sob diferentes denominações, formaram-se movimentos que reivindicavam um papel especial para os cientistas, no sentido de evitar novas ameaças para o ambiente e a vida em si. Isto incluía o abandono das armas nucleares, a preocupação com os países em desenvolvimento e os cuidados com todas as formas de vida selvagem. Os tópicos envolvidos realmente tinham alguma relação com a ciência ensinada nas escolas, mas o que era novo era a ênfase na responsabilidade social na ciência, na ética e nos valores cívicos.

Em 1970, foi formado o primeiro movimento educacional Ciência num Contexto Social (Science in a Social Context - SISCON), por W.F. Williams, da Universidade de Leeds. Em 1976 foi realizado um encontro com o movimento STS holandês em Amsterdam, e em 1979 emergiu o ramo escolar do SISCON (Solomon, 1980).

1 Também conhecido pela sigla CTS (nota da tradutora). 
Existe alguma forma de redescrever, em termos de um modelo evolutivo, a forte e quase simultânea emergência do movimento STS na Inglaterra, Holanda, nos Estados Unidos e no Canadá? A natureza quase digital dos genes, que tão bem explica a herança biológica, não consegue descrever de forma satisfatória tendências culturais penetrantes, unidirecionais, que não ocorrem em etapas isoladas. Para tal explicação, talvez seja necessário ressuscitar o velho modelo lamarckiano, pelo qual as variações adquiridas diretamente a partir do meio ambiente, são herdadas e estão prontas para melhorias adicionais. Mas, mesmo assim, a distinção não seria tão significativa. Avanços recentes na biologia mostram que o ambiente afeta a expressão dos genes e, portanto, a manifestação no fenótipo.

Isto coloca um problema inteiramente novo para a CPD dos professores de ciências, que parece nunca ter sido resolvido. Vários livros foram muito poderosos no sentido de mudar o pensamento das pessoas, mas não fizeram nenhum contato com o ensino e a sala de aula. Livros semi-populares como os de Rachel Carson, de Theodore Rojzac e, posteriormente, de Ulrich Beck foram influentes, mas também ameaçaram o ensino de ciências. Teria sido possível apresentar esta relevância e atualidade, que provocaram tanto reações emocionais como considerações sobre responsabilidade, sem trazer uma polêmica prejudicial contra a própria ciência, que sempre foi encarada como sendo eticamente neutra? A educação superior almejava ter suas iniciativas STS reconhecidas pelos padrões acadêmicos. A nova tendência cultural da responsabilidade social na ciência era para ser identificada e incluída, sem todavia prejudicar as antigas normas da ciência acadêmica válida. A infame "Guerra das Ciências" ainda não estava ameaçando todos os estudos sociais da ciência.

\footnotetext{
Não é uma questão de subverter radicalmente os cientistas e as instituições tecnológicas já estabelecidas, nem de desviar a principal corrente do ensino de ciências de seus rumos tradicionais. A saúde do empreendimento científico depende das pessoas terem uma visão muito mais precisa da ciência e da tecnologia, do que elas obtêm dos currículos já existentes. As pessoas precisam ter acesso à caixa preta que contém a ciência, entendida como um instrumento para a ação social. Este deve ser o objetivo fundamental do movimento para a educação STS - não o de substituir a educação tradicional em ciências, nem de modificá-la a ponto de não ser mais possível reconhecê-la, mas de corrigir seus desvios inconscientes com temas complementares. (Ziman, 1980, p.53)
} 
O que a maioria dos professores reflexivos queria do movimento STS era o conhecimento relevante, que poderia realmente interessar a seus alunos, e uma oportunidade para que estes tivessem um papel nas discussões (Giroux, 1997) em meio ao ambiente relativamente silencioso do aprendizado de ciências. Um ensino de ciências baseado em questões amplas pode até atrair o interesse daqueles alunos que geralmente não se matriculam em disciplinas científicas optativas (como era o caso, na época). De qualquer forma, aquele era um momento de mudanças, quando os professores que foram os originadores das estratégias STS queriam produzir métodos mais ativos de aprendizado que motivassem a participação dos alunos.

Nos anos 70 e 80, concomitante ao surgimento das iniciativas STS mas dissociado destas, o educador britânico Malcolm Skilbeck publicou sua discussão sobre os objetivos dos currículos escolares. Ele propôs que um dos dois propósitos da educação como um todo era fornecer, à próxima geração, as habilidades para criticar a sua própria cultura.

... Um plano curricular numa escola pode ter como objetivo incentivar o pensamento reflexivo: pode estimular e fornecer oportunidades para a participação em projetos práticos, dos quais a própria comunidade se beneficia; pode encorajar os alunos a se enxergarem como os organizadores de sua própria sociedade. (Skilbeck, 1975, p. 34)

Este tipo de reflexão foi tão surpreendente quanto o próprio surgimento do movimento STS, e não independente dele. Agora podemos ver o movimento STS como parte de uma mudança muito mais ampla, na qual a educação era uma preparação para uma 'reconstrução social' pelos cidadãos, cujas decisões sobre as novas tecnologias e valores sociais eram essenciais.

Portanto, parece que a educação STS estava surgindo no ritmo de um desejo de mudanças em duas áreas, na universidade e na escola. Mas então, na época do rígido Currículo Nacional Britânico, o ambiente educacional tornou-se muito hostil para essa nova 'espécie', e o seu fenótipo foi eliminado temporariamente. Na atualidade, a educação em ciências está lentamente revertendo no sentido de um desejo de educar para as questões sociais e cívicas. Mais uma vez o movimento STS está emergindo, o que vem sendo expresso por atividades coletivas de uma minoria de professores na Inglaterra e também no Brasil.

Nesse contexto, a CPD pode assumir um papel bem diferente do anterior. As iniciativas STS tiveram seu início como um movimento para a 
responsabilidade social na ciência; portanto, é possível que seja necessário explicar aos professores alguns aspectos de sua origem social, histórica e cultural. Contudo, a segunda e mais importante necessidade é a de encorajar os professores a proporem métodos apropriados para o ensino de STS. Isto estimulará o profissionalismo continuado de nossos professores de ciências, ampliando sua contribuição essencial para as importantes mudanças curriculares na sala de aula (ver também Parke e Coble, 1997).

\section{RESUMO}

O artigo trata da discussão sobre a profissionalização dos professores a partir das experiências e discussões produzidas principalmente na Inglaterra e nos Estados Unidos. O artigo sustenta que os professores constituem o patrimônio cultural mais importante na educação de um país, e o principal patrimônio destes não é o domínio de conteúdos específicos ou pedagógicos per se, mas sim o seu status social, tanto aos olhos da comunidade como aos seus próprios olhos.

\section{REFERÊNCIAS BIBLIOGRÁFICAS}

APPLETON, K. Student teachers' confidence to teach science: is more science knowledge necessary to improve self-confidence? International Journal of Science Education. v. 17, n. 3, p. 357-369, 1995.

CAMPBELL, D. Blind variation and selective retention in creative thought as in other knowledge processes. Psychological Review. v. 67, n. 6, p. 380-400, 1960.

. Variation and Selective Retention in Socio-cultural Evolution. In: (Ed. Barrington, H., Blankston, G. \& Mack, R.) Social Change in Developing Areas. Cambridge Mass. Schenkman. p. 21-49, 1965.

DENNETT, D. True Believers: the Intentional Strategy and why it works. In: (Ed Heath, A. F.)Scientific Explanation. Oxford. Clarendon Press. p. 53-75, 1981.

DOUGLAS, M. How Institutions Think. London. Routledge Kegan Paul, 1987.

DUSCHL, R. Restructuring Science Education. New York: Teachers College Press, 1990.

ELLIOT, J. A model for professionalism and its implications for Teacher Education. British Journal of Educational Research, v. 17, n. 4, p. 309-318, 1991. 
FLECK, L. The Genesis and Development of a scientific fact. Trans. 1979 Chicago: University of Chicago Press, 1935.

GIROUX, H. Pedagogy and the Politics of Hope: Theory, Culture and Schooling. Oxford. Westview, 1997.

HANDAL, and LAUVAS. Promoting Reflective Teaching; Supervision in Action, (SRHE and Open University Press.), 1987.

HARLAND, J. and KINDER, K. Mathematics and Science Courses for Primary Teachers: lessons for the future. (Slough. NFER.), 1997.

KUHN, D. Education for Thinking. Teachers' College Record. v. 87, n. 4, 1986.

KYLE, W. C. What became of the curriculum development projects of the 1960 ? In: D. HOLDZCOM, and P.B. LUTZ (Eds) Research within reach: Science Education. (Charlston, Appalacia Educational Laboratory.), 1984.

LEVACIC, R. Competing for Resources: the impact of social disadvantage and other factors on English secondary schools' financial performance. Oxford Review of Education, v. 24, n. 3, p. 303-328, 1996.

PARKE, H. and COBLE, C. Teachers Designing Curriculum as Professional Development: A model for Transformational Science Teaching. Journal of Research in Science Teaching, v. 34, n. 8, p. 773-790, 1997.

POPPER, K. Objective Knowledge. (Oxford, Clarendon Press.), 1972.

RADFORD, D. Transferring Theory into Practice: a model for Professional Development for Science Education Reform. Journal of Research in Science Teaching, v. 35, n. 1, p. 73-88, 1998.

ROBERTS, D. Theory, Curriculum development and the unique events of practice. In: (Ed. MUNBY, ORPWOOD and RUSSELL) Seeing Curriculum in a new Light. (Toronto, OISE Press.), 1998.

SCHON, D. The Reflective Practitioner. How professionals think in action. (London, Temple Smith.) SKILBECK, M. (1975) The School and Cultural Development. In (ed. GOLBY, M., GREENWALD, J. and WEST, R. Curriculum Design. Milton Keynes. Open University Press, p. 7-19, 1983.

SOLOMON, J. Signs of change in the Science Class. New Scientist. Feb 5th, 1987.

. Science and Society Studies in the Curriculum. School Science Review. v. 82, p. 213-220, 1980.

VESILIND, E. and JONES, M. Gardens or Graveyards: Science Educational. Reform and School Culture. Journal of Research in Science Teaaching, v. 35, n.7, p. 757-775, 1998.

WAUGH, R. and GODFREY, J. Teacher receptivity to System-wide Change in the Implementation Stage. British Educational Research Journal, v. 19, n. 5, p. 565-578, 1993.

ZIMAN, J. Reliable Knowledge. Cambridge: Cambridge University Press, 1978. . Teaching and Learning about Science and Society. Cambridge: Cambridge University Press, 1980. 